\title{
Reflecting on lecturer dispositions to decolonise teacher education
}

\section{Heloise Sathorar}

Faculty of Education, Nelson Mandela University, Port Elizabeth, South Africa

Heloise.Sathorar@mandela.ac.za

https://orcid.org/0000-0002-4947-0885

\section{Deidre Geduld}

Faculty of Education, Nelson Mandela University, Port Elizabeth, South Africa

Deidre.Geduld@mandela.ac.za

https://orcid.org/0000-0001-6175-0508

(Received: 19 February 2019; accepted: 11 September 2019)

\section{Abstract}

An increasingly diverse student population is becoming the norm at South African universities with culturally and linguistically complex classrooms being the reality. Lecturers are challenged not only to prepare students to participate in an increasingly diverse context, but also to respond to such diversity within their own sites of learning and teaching. Most of the current lecturers at higher education institutions (HEIs) were schooled during the apartheid era, and were predominantly exposed to Western ideologies and fundamental pedagogics. This complicates curriculum transformation at HEIs because lecturer dispositions need to be revisited to bring about the change required to address the needs of the new generation of students. Despite the transformation and curriculum renewal efforts at universities in South Africa, students still claim that they feel the effects of colonialism in lecture halls and in the rendition of the curriculum-and they call for the decolonisation of the curriculum. Changing the curriculum without changing the lecturer is especially difficult under conditions of radical social transformation. Changing the curriculum too far ahead of the lecturers who have to implement it, is unlikely to rearrange the epistemological order of things in the classroom. This paper seeks to understand lecturer dispositions to decolonise teacher education, and proposes a framework to enhance these dispositions to engage with decolonisation.

Keywords: curriculum transformation, decolonisation, teacher education 


\section{Introduction and background}

More than 20 years after the first democratic elections in South Africa (SA), it is evident that the euphoria of liberation from apartheid has made way for a realisation that the deeply entrenched inequalities and injustices are still prevalent in the country's social construct. South Africa's private and public sectors continue to battle with this dilemma and public higher education is no exception (Suransky \& van der Merwe, 2014). Higher education in the postapartheid era has never been more volatile than it is currently. The higher education sector in South Africa currently is very different from its fragmented, insular, elite, and uneven apartheid past. However, the legacy continues to shape and influence the sector in less desirable ways, and the stresses exerted by the challenging socioeconomic context of the country are having a far-reaching effect on the quality of the sector as a whole. Bozalek, Carolissen, and Leibowitz (2013, p. 40) concurred, suggesting that "the apartheid-designed, segregated higher education institutions (HEIs) continue to have a major influence on students and lecturers in South Africa."

For the past two decades, higher education institutions in South Africa have been exploring ways in which they can make their curricula more responsive to the needs of the new generation of students and to the community it serves. Despite extensive efforts, students still claim that they feel the effects of apartheid in the lecture halls and in the rendition of the curriculum. Soudien (2015) highlighted that shifting knowledge regimes is intensely difficult. Jansen (2009) concurred with this notion and suggested one of the reasons for this being that lecturers themselves are burdened by their own histories and prior experiences, which influence their ability and preparedness to mediate dialogue on difference. He further postulated that:

Changing the curriculum without changing the curriculum maker is especially difficult under conditions of radical social transformation. Changing the curriculum too far ahead of the teachers who have to implement it, is unlikely to rearrange the epistemological order of things in the classroom. (Jansen, 2009, p. 179)

It is thus, important to ensure that those who implement a new curriculum have the necessary disposition to bring about the envisaged transformative goals of the curriculum. This paper reflects on the findings of a qualitative investigation of lecturer dispositions regarding decolonising a teacher education curriculum. Furthermore, the paper draws on literature regarding dispositions as well as the decolonisation of a teacher education curriculum, and shares the findings of the study. In conclusion, a framework with some guiding questions and suggestions regarding how to enhance lecturer dispositions on decolonising a curriculum is presented.

\section{Problem statement}

The recent Fees Must Fall students' action can be seen as an attempt by students to reject the colonised mentalities they claim prevail in universities and that oppress their knowledge 
through a form of epistemicide (Santos, 2014). Students voiced the need to make sense of their positionality in a world characterised by the exclusion and marginalisation of black students on the basis of class, race, and gender (Fataar, 2018). HEIs seem to remain vulnerable to ongoing systematic and institutional racism and consequent socioeconomic structures of poverty and privilege (Bozalek, Carolissen, \& Leibowitz, 2013). These conditions have only worsened in SA with the steady increase of neoliberal imperatives to control higher education policy and institutional structures.

Increasingly, students question the relevance of the curriculum they are taught. The lecturers are central to the pedagogic project of the university, and their disposition influences the way they teach (Palmer, 1997; Sathorar \& Geduld, 2018). In examining the influences of lecturer dispositions on the curriculum, we must first look at the notion of dispositions. In this context, dispositions are the principles, commitments, values, and professional ethics that influence attitudes and behaviours towards students (The National Council for the Accreditation of Teacher Education Council, 2006). The challenge with the dispositions of the current lecturers at universities is that most of them were schooled in a colonised system. This thus impacts the way they think about the curriculum and the implementation thereof. Banks (2003, p. 6) postulated that lecturers perpetuate their own "political values, beliefs, myths, and meaning about the world" within lecture halls.

One way to contribute to the decolonisation of education is by changing the disposition of those who are responsible for implementing the curriculum. Freire wrote that humans are conditioned by structural and institutional forces - but are not determined by them; the fact that we are able to be conscious of that conditioning, means that we can transcend it (1994, 1998a, 2004, 2007). He continually emphasised the fact that humans are unfinished, and our unfinishedness suggests our constant search for deeper understanding and social, personal, and professional transformation. Therefore, lecturer dispositions are not static and can be changed.

In this paper, we strive to understand and explore lecture dispositions in our faculty, and propose a framework to enhance lecturer dispositions to engage with decolonisation. Lecturers need to be aware of their own dispositions, which could isolate students through the notions of knowledge construction, power, and mistrust. We used the following three questions to guide our discussions:

- What are your beliefs and feelings about decolonisation?

- Do you believe that you are engaging in decolonised practices in your classroom?

- How can we enhance lecturer dispositions to engage positively with decolonising the curriculum?

Ngũgĩ wa Thiong'o (1981) postulated that education is a means of gaining knowledge about ourselves. After we have examined ourselves, we radiate outwards and discover people and worlds around us. In this light, lecturers reflecting on their own dispositions towards decolonising the curriculum becomes crucial to transformation in higher education. 


\section{Literature review: Lecturer dispositions regarding decolonising a teacher education curriculum}

\section{Decolonisation}

Decolonisation as a process allows one to engage with the historical legacies of intellectual colonisation and racialisation and patriarchy in our curriculum (du Toit, 2000, as cited by Ramoupi, 2014). It involves the reclamation of new ways of relating to one another that entail the co-creation of new possibilities and the transformation of political and personal histories (Goulet, Linds, Episkenew, \& Schmidt, 2011). Mbembe (2015, p. 6) further claimed that decolonising the university has to do with "creating a set of mental dispositions." The mental dispositions that need to be nurtured are in line with what Oelofsen (2015) has been calling the decolonisation of the mind. In this paper, we emphasise the call for academics as transformative intellectuals to make their voices and perspectives heard in the university and in the intellectual landscape. This will require them to be engaged in self-reflection with their own teaching and learning context.

Decolonising the curriculum can mean different things: it includes a fundamental reconsideration of who is teaching, what the subject matter is, and how it is being taught (Geduld \& Sathorar, 2016). Decolonisation asks us to consider how the disposition and identity of a lecturer shape their perspectives. How the design of the lecturer's modules entails narrating stories and knowledges; thus, we need, as lecturers, to reflect more critically on how these stories are told and knowledges shared. Which actors are privileged and placed at the centre of our teaching and learning? Whose voices are authoritative and considered part of the core teaching while others are left at the margins (Battiste, 2013)? In this paper, we argue that decolonisation is an ongoing process of becoming, unlearning, and relearning of who we are as lecturers, and of taking responsibility for curriculum design and what our students learn.

\section{Lecturer dispositions}

Bourdieu (1998, p. 87) defined habitus as a "system of continuous and transferable dispositions." According to him, disposition means the individuals' positions and tendencies in terms of the particular way they think, feel, act, and understand. Furthermore, they embody and internalise - not in a conscious way, but through pedagogical processes and socialisations at the base of the objective social conditions of their existence and of their social orbit (Bourdieu, 1998). Asimaki \& Koustourakis (2014) emphasised that dispositions tend to function as non-conscious principles that guide practice and, in general, perception as well as every reaction of the individual. These acquired dispositions define how each person understands, realises, and evaluates social reality because they guide the formation of the behaviours and strategies they choose in the various social fields in which they participate (Bourdieu, 1990a). Habitus "is not fixed or permanent and can be changed under unexpected situations or over a long historical period" (Navarro, 2006, p. 16). 
Similarly, Villegas (2007) argued that dispositions are tendencies for individuals to act in a particular manner, under particular circumstances, based on their beliefs. In analysing the above definitions of dispositions, Bondy, Beck, Curcio, and Schroeder (2017) argued that for them the term, dispositions, encapsulates both beliefs and actions, and they rejected the notion that dispositions are purely based on one's personality and can therefore not be changed. Thus, they defined dispositions as the context specific manifestations, whether mental or physical, of one's beliefs and actions that, while predictable, are nevertheless capable of being changed over time. Splitter (2010) argued that dispositions move beyond what people might know or be able to do at the current moment, and incline towards what may be possible for a person to do in terms of their conscious mental state, thereby alluding to the fact that a disposition can be learned. Bondy et al. (2017) posited that certain beliefs, values, and attitudes, when honed and developed over time, can create a certain disposition.

Lecturers in HEIs develop dispositions that determine their approach to students, and which are formed as a result of the knowledge and experience they have acquired during previous experiences and actions in the different social fields of their education and training, and from their professional occupation with diverse students (Bourdieu, 1977, 1990a; Swartz, 1997). These dispositions are incorporated into lecturers' daily practices and guide their pedagogical choices for the education of students in their classrooms. Habitus consists of embodied social knowledge, and is detected in the practical effects of a person's actions, in their way of speaking, in their perceptions and in the arguments they express on specific issues (Bourdieu, 1990b) — such as the decolonisation of education. Bourdieu (1977) used the concept hysteresis effect to describe a type of relationship between habitus and field (social structure; Asimaki \& Koustourakis, 2014; McDonough \& Polzer, 2012). The dispositions (habitus) of a person are shaped by the social structure (field) and they change "in response to new experiences" (Bourdieu, 1977, p. 161). Moreover, changes in the rules of a field, such as the decolonisation of HEI, will not usually produce quick changes in the dispositions of actors like lecturers. The hysteresis effect is the experience of mismatch caused by the temporal lag between a person's disposition and a changing social structure (Bourdieu, 1984, 1990b, 1998). People tend to maintain the dispositions already acquired—even when they do not fit the new situation. More specifically, Bourdieu argued:

As a result of heightened consciousness associated with an effort of transformation . . there is an inertia (hysteresis) of habitus which has a spontaneous tendency to perpetuate structures corresponding to their conditions of production. As a result, it can happen that ... dispositions are out of line with the field and with the "collective expectations" which are constitutive of its normality. (1977, p. 160)

In this light, Sardar (2008) was of the opinion that much has changed in the world, however, the underlying structures of oppression and injustice remain the same. Similarly, Mbembe (2016, p. 32) argued that "there is something profoundly wrong when . . syllabuses designed to meet the needs of colonialism and apartheid should continue well into the liberation era" in South African HEIs. Therefore, epistemological change at HEIs is much needed. According to Heleta (2018), white academics remain in the majority at HEIs in SA, whilst one of the 
failures of decolonisation has been the lack of curriculum transformation at these institutions. $\mathrm{He}$ is of the opinion that curricula at universities remain Eurocentric, rooted in colonial and apartheid knowledge systems, and disconnected from the realities and lived experiences of black South Africans. Thus, changes in the field of curriculum transformation in HEIs require lecturers to revisit their dispositions regarding decolonisation. Consequently, many of the lecturers who work in HEIs may experience the hysteresis effect, that is, a lag in their dispositions adjusting to the required curriculum transformation in contemporary lecture halls.

In this hysteresis, lecturers find themselves in a place of internal struggle that can be categorised into a place of resistance, a place of inertia, and a place of possibility. The place of resistance is characterised by refusal to change-refusal to engage on issues of decolonisation, and arguing for maintaining the purity of the discipline. The place of inertia is a place where thinking has stopped. The person acknowledges the importance of engagement, but the engagement is not translated into action. The place of possibility demands that critical consciousness be translated into action, and requires liberatory praxis regardless of the risks.

Mitchie (2012) and Bondy et al. (2017) suggested that in order to enhance lecturer dispositions, various values should be honed and supported. These values include radical openness, humility, and self-vigilance. In the same light, Bautista (2018) proposed that the values of haven, community, love, healing, agency, and creation be honed and supported to develop a transformative lecturer disposition framework. In our discussion of lecturer dispositions, we utilise the metaphor of the butterfly that is centred in love and propelled by the wings of community and healing. The butterfly represents lecturer dispositions that strengthen its wings of community and healing through acts of agency and creation within the context of a haven (see Figure 1).

In the higher education sector, the neoliberal assaults on people have created toxic and violent environments (Ginwright, 2010; Gordon, 2010; Lipman, 2011) that signal a need for safe spaces for intellectuals to work in. Establishing a haven-a counter-hegemonic space that supports the creation of alternative structures, practices, and relationships towards democratic and liberatory aims (Darder, Baltodano, \& Torres, 2009)-would enhance the pursuit of transformation in this sector. Freire (1970) postulated that an authentic transformation is marked by the communion of people through a collective engagement in praxis. He called for decolonial approaches that decentre colonial hierarchies and dignify the experiences of the people. According to him, this can be marked by a shared commitment to disrupt the tension people experience internally, interpersonally, institutionally, and ideologically. He was of the opinion that, through the promotion of community, the growth of counter-hegemonic spaces is critically disrupted. 


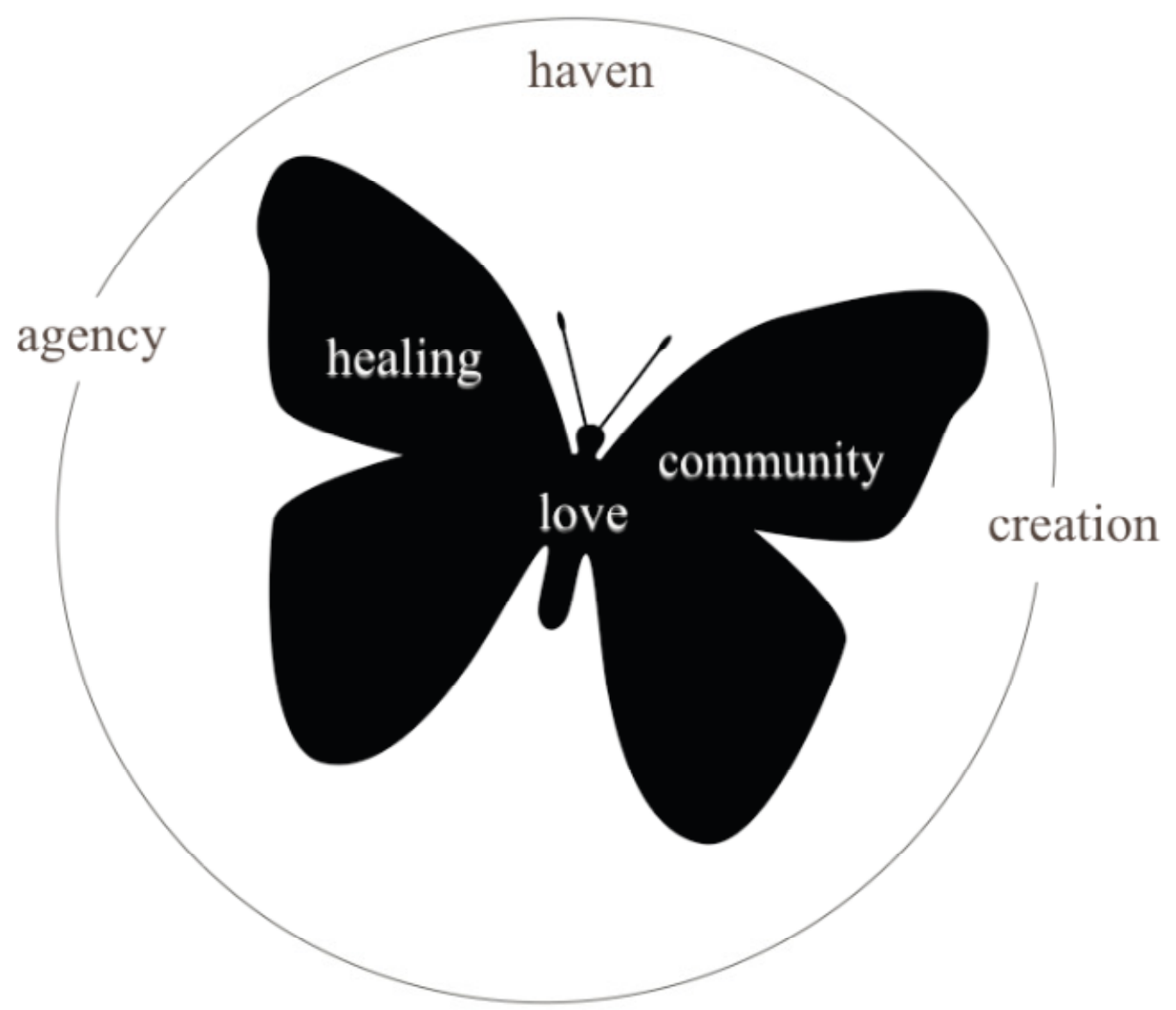

Figure 1: A visual summary of the transformative lecturer disposition framework (Bautista, 2018, p. 225).

Darder (2015, p. 49) referred to love, as represented by the centre of the butterfly, as "an intentional spiritual act of consciousness that emerges and matures through our social and material practices, as we work to live, learn, and labour together." Furthermore, she postulated that, it demands "our shared curiosity, creativity, and imagination, giving meaning to both our resistance and counterhegemonic practice" (Darder, 2015, p. 50). The aim of the "healing" wing is to facilitate the epistemological healing and unity of the body, mind, spirit, and heart because colonial epistemicides have systematically divided the unity between bodies and minds (De Sousa Santos, 2014). The acts of agency and creation in the sphere of the haven are means for democratic communities to dismantle colonial institutions and epistemologies through meaningful collective action in order to create a new world. We draw on Bautista's (2018) metaphor of practice to propose a framework to enhance lecturer dispositions to engage with decolonisation.

\section{Methodology}

Freire (1998a) urged teachers to reject their domesticating role and work to challenge the authoritarianism of standard policies and practices of pedagogy, curriculum, and school administration that require an open process of dialogue. Using dialogues as research methodology, we believe, assists participants to tell their personal histories and to access their 
political rights. The use of this methodology enabled participants to remain radically open, humble, and self-vigilant.

\section{Data collection strategy}

This study was based in the faculty of education at Nelson Mandela University, and formed part of a bigger process of curriculum renewal. For this particular paper, the data collection was arranged through a series of focus group discussions with 20 faculty members from across all the programmes offered in the faculty. The table below provides an overview of the profiles of the participants. It was important to establish the profiles of participants because we tried to ensure that the participants were representative of faculty staff in terms of gender, race, and age. More than half of the faculty staff at the time of this investigation were older than 50 years. This is significant in that it highlights the fact that the majority of staff members in the faculty were schooled and trained as teachers during the apartheid era when most of the state-funded HEIs and teacher training colleges were complying with the policies of the apartheid regime.

Table 1: The biographical details of our participants

\begin{tabular}{|l|l|}
\hline \multicolumn{1}{|c|}{ Biographical category } & \multicolumn{1}{|c|}{ Participant profile } \\
\hline Gender & Female: 10 \\
& Male: 10 \\
\hline Race & Black: 7 \\
& Coloured: 1 \\
& Indian: 2 \\
& White: 10 \\
\hline Age & $50-55$ years: 5 \\
& $55-59$ years: 5 \\
& $60-65$ years: 10 \\
\hline Previous institutional affiliation & NMMU: 5 (joined after the merger) \\
& PE Technikon: 4 \\
& UPE: 8 \\
& Vista (PE): 3 \\
\hline
\end{tabular}

Data was obtained from focus group discussions to gain direct responses and views from participants regarding the research questions (Lincoln, Lynham, \& Guba, 2011). This allowed participants to "build explanations" (Rubin \& Rubin, 2012, p. 5) from what was being discovered collectively regarding the research questions. Leedy \& Ormrod (2005) maintained that information gained from participants voicing their perceptions and understandings of a topic during focus group discussions can be a useful source of data. Furthermore, Taylor and Medina (2013) postulated that the dialogical engagement during focus group discussions is suited for a critical paradigm because it is characterised by collaboration, active and voluntary participation, and open, frank, democratic communication. In our focus group 
discussions, we evaluated and interrogated participants' (faculty) agency in trying to understand these questions:

- What are your beliefs and feelings about decolonisation?

- Do you believe that you are engaging in decolonised practices in your classroom?

- How can we enhance lecturer dispositions to engage positively with decolonising the curriculum?

The questions would assist us in understanding the individuals' disposition and tendencies in terms of the way they think, feel, act, understand, and which they have embodied and internalised-as proposed by Bourdieu (1998). We sought to empower participants by critically looking at the practical implementation of decolonising the curriculum in our faculty. In addition, this look at practice allowed us to self-critique our own practice and provided alternative pathways to improving it.

Once the research questions were posed, participants were encouraged to freely engage with the questions. These focus group discussions proved to be journeys of inquiry that led us to multiple perspectives and uncharted pathways regarding decolonisation. Occasionally, the researchers as facilitators were asked what their opinions were-however, we had to stay neutral and guide the discussion by posing further questions to be reflected on. The researchers posed probing questions that entailed requesting participants to comment or ask questions about what another participant had said. This ensured that the discussion flowed, and allowed for the eliciting of deeper meaning on certain aspects. The discussion resulted in a dynamic and reflexive process of sharing stories and experiences by faculty members on the topic of decolonisation. Participants used this space to critique themselves: they drew into debates, challenged their reasoning, and emerged from the discussions with heightened critical understanding of their practice. Even before the data was analysed, and just by general observation of the process, the researchers noted that participants-by their own admission-felt that the discussions had allowed them to gain better understanding regarding decolonisation, and how it created opportunities to learn and to try new things. Some said that the discussions just confirmed what they already knew and were practising, whilst others admitted that the discussions left them with several questions. The discussions also illuminated the challenges of decolonising the curriculum within a complex higher education space that was not actively supportive of decolonisation, with white academics still being in the majority.

\section{Data analysis}

The focus group discussions were videotaped and audio taped to allow us to capture interactions between researchers and participants. Miles and Huberman (1994) stated that data analysis comprises the interaction and interrelatedness of reducing, displaying, and drawing conclusions from the data collected. After making verbatim transcriptions of the focus group discussions, we checked the accuracy of the transcriptions against the audio recordings (Ravitch \& Carl, 2016). The transcripts were read repeatedly to familiarise ourselves with the data and to identify possible themes. The data was coded, and the initial 
themes were handwritten on the transcriptions (Braun \& Clarke, 2006). The dialogic narrative analysis was reviewed at a follow up session and consensus was reached amongst participants that the data was correctly analysed and captured.

\section{Findings and discussion}

As described above, this study sought to investigate lecturer dispositions with regard to the decolonisation of the curriculum. In this section, we provide a summary of the analysed data. Drawing reference from Bourdieu's (1998) definition of disposition, we asked lecturers about their feelings and beliefs about decolonisation. In this light, Freire and Macedo (1995) postulated that one knows with one's entire body-with feelings, with passion, and also with reason. It is your entire body that socially knows. You cannot, in the name of exactness and rigor, negate your body, emotions, and feelings (Freire \& Macedo, 1995). Most participants had positive feelings about decolonisation, and highlighted the importance of engaging with the topic. One of the participants made the following comment:

Decolonisation is absolutely needed in South Africa to bring about true change. It will allow both lecturers and their students to think and reflect critically about their practices and to resist the dominance of one culture as well as to focus on bringing about the required change in South Africa.

Additional viewpoints included:

Decolonisation sets individuals free from ways of thinking that inhibits their creativity and uniqueness.

It will empower individuals to realise that they have a meaningful contribution to make to their communities.

It will encourage individuals to take responsibility for the retention of their heritage and unique identities by resisting any pressures which outside forces may exert to make their cultures appear less worthy than any dominant culture or language.

Furthermore, participants also reflected on the role that decolonisation plays in promoting diversity and social justice. The following quote serves as evidence:

Decolonisation allows for the acknowledgement of different cultures and languages, and highlights the importance of taking note of power relations in the pursuit of social justice.

Despite the mostly positive feelings about decolonisation, some reservations were raised including how students would manage the matter of empowerment, and whether students know what they needed to learn. Participants also reflected on how one would accommodate all the different voices in a class, as can be seen from the following statement by a participant: 
How will one be able to ensure that all voices are equally represented in a curriculum and in class?

We further pursued the matter by asking whether the participants believed that they were engaging in decolonising practices in their classrooms, and asked them to cite examples of these practices. There were several examples cited, which provided evidence that some lectures were indeed engaging in practices that supported the cause of decolonising the curriculum in their classes, as can be seen from the following participants' statements:

I teach in the Socratic style; I am very disruptive and challenging of existing thoughts. I challenge privilege and other hegemonic ideas, norms and standards. I provide readings which seek to cause discomfort and present alternative viewpoints.

I provide my students with provocative text and encourage them to read for meaning by looking for the literal meaning, inferential meaning and the personal meaning. It is the personal meaning that allows them to interact with the text and to ask questions. It is during this process that student voice comes out and where lived experiences are shared.

The examples above accentuated the importance of lecturers and students engaging in a mutual quest for knowledge and understanding, that lecturers and students are equal partners in this process, and the importance of constantly raising consciousness through dialogue and problem posing strategies. Another viewpoint that was strongly communicated was the importance of involving students in curriculum decisions. A participant had the following to say in this regard:

We need to decolonise the way we teach; we cannot proceed as in the past, as valuable information was lost due to the emphasis on Western societies and knowledges.

Participants explained that they encouraged students to think for themselves by drawing on their own lived experience in the teaching process. Lecturers need to be open to sharing their power in class with students (Freire, 1994). They need to take local content and context into account (Sathorar \& Geduld, 2018), challenge dominant thinking and power relations (Freire, 1970), respect and give prominence to all cultures (Freire, 1978) and languages-ensuring that language is not used as a tool to disempower specific groups (Alexander, 2014). Several dissenting views as well as concerns about applying decolonising practices were also raised. Some participants indicated that engaging in these practices was time consuming and that sometimes students would get irritated by the process. The following statement refers:

Many students do not appreciate my problem-posing approach and enquiring methods. They prefer a more direct, transmission style as they do not want to think and reflect on their thinking and understanding of what we grapple with in the classroom. They find self-discovery and engaging in discussions daunting, and I literally have to force them to participate. 
The fact that what we teach is determined by prescriptive policies, and how we teach is limited by institutional regulations, also hampers the implementation of decolonising practices. A participant made the following statement in this regard:

Engaging in decolonising practices is often impeded by prescribed curriculums and restrictive institutional regulations, like timetables.

Although most participants indicated that they were engaged in decolonising practices, there were several who also indicated that for various reasons they did not address decolonisation in their classes. There were some participants who mentioned that they did not know how to implement decolonising practices in their classrooms as the following statement illustrates:

Despite having an idea of what decolonisation entails, I find it difficult to put these principles into action in my classes.

What became evident is that, in some cases, lecturers used the above excuse to knowingly or unknowingly not engage with decolonising practices.

The data analysis also revealed a lack of agency to engage with decolonisation practices. There needs to be a willingness to engage on the topic as well as implement practices that will enhance decolonisation. The study found that people were set in their ways of doing things, and that they found it difficult to engage with the matter of decolonisation. The following comment refers:

I am not implementing decolonisation practices to the extent that I should be. I wish I could blame the system of education that produced me, but I can't. After so many years at the university, I should have no excuses. I need to revise my ways of being, thinking, and doing.

Based on the analysis provided above, the tension of lecturers being in a place of resistance (not willing to change), inertia (having many questions), and possibility (seeing opportunities to learn) was evident. The above concerns gave impetus to the following question: What is required to enhance lecturer dispositions regarding decolonisation, and how can they be encouraged to participate in decolonising practices? In other words, how can we support lecturers to reach a place of possibility? There was a strong request for support from academic structures through more flexibility in taking the curriculum beyond formal bureaucratic boundaries including fixed timetables and pre-determined assessments. Sadeghi (2008) described how lonely and isolated she felt at work when she tried to engage with decolonisation by applying a critical approach in her classroom. She described how she was frowned upon for touching on complex topics, and how difficult it was to examine biased voices in every different context. Having a supportive institutional environment (haven or safe space) would encourage lectures to engage in decolonisation matters. Participants also made an earnest appeal for exposure to experts on the topic as well as for implementable examples. Pruyn and Malott (2013) suggested that lecturers would be encouraged to engage in critical practices such as decolonisation if there was strong leadership that believed in the 
power of exposure and collaboration. They postulated that working collaboratively as a community would encourage lecturers to experiment with approaches and strategies in their classrooms that would enhance the decolonisation project. The importance of linking what is being taught in class to the students lived experience was strongly emphasised, and lecturers indicated a need for agency to take what is being discussed in class into the society.

\section{Suggestions}

Drawing on the above analysis and more specifically on the requirements indicated by lectures that would encourage them to engage in decolonising practices we would like to propose the following framework of practice as a tool to enhance lecturer dispositions as well as their willingness to engage in decolonising practices. The table below indicates elements of the framework that could assist lecturers who finds themselves at various places of the decolonisation project to develop a positive disposition towards decolonisation, and encourage engagement with the topic.

The participants committed themselves to the following vision for continuous revisiting of lecturer disposition and the decolonisation of teacher education. As agents of change, we reflect and respond to the elements of the place where our teaching and learning happen. We recognise the inherent political nature of the curriculum, the pedagogies we adopt, and the unequal society we find ourselves in. However, we remain mindful that we will learn, unlearn, and relearn as we move through these places of reflection where nothing is static but always in motion (Mackinlay \& Barney, 2012).

Table 2: Places to enhance a disposition of possibility to engage with decolonisation

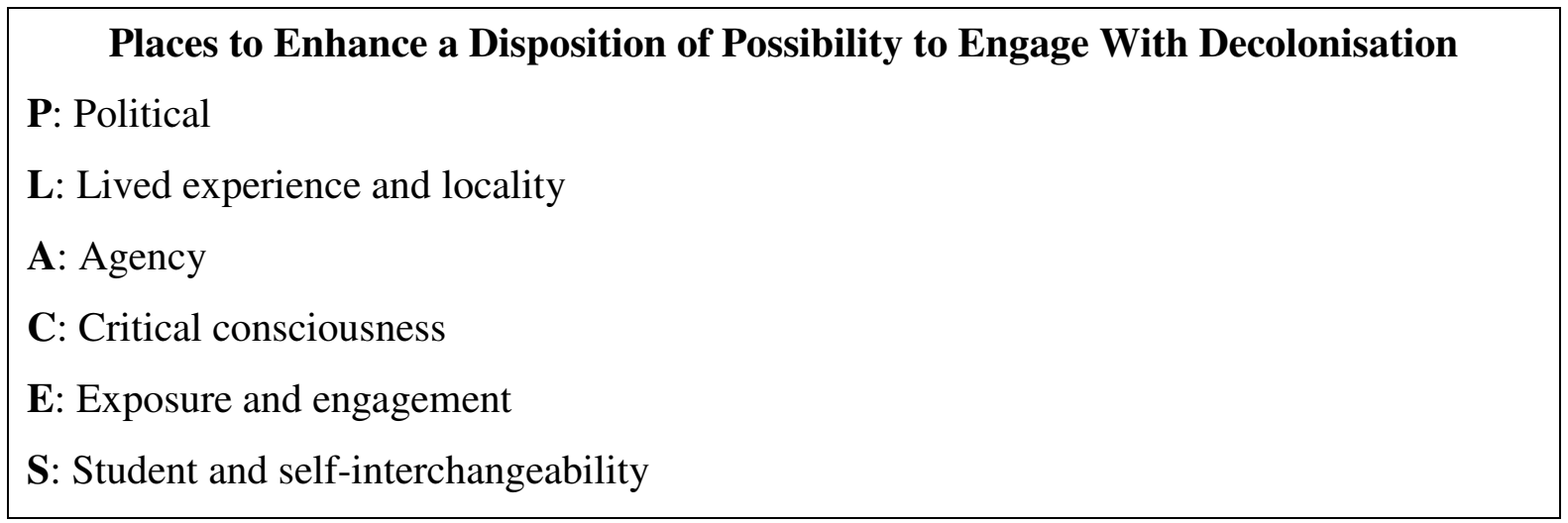

We formulated a number of guiding questions (Freire \& Shor, 1987) for each letter of the word "places" where lecturers find themselves in the struggle with their own disposition.

\section{P: Political}

As lecturers and students, we need to continuously read the world where our work is situated in a society, which we gradually need to look at more critically. The world where our work is situated refers to the haven in Figure 1. The haven is intended to be a safe space where lecturers are encouraged to have an opinion and not to be neutral about issues. It is 
impossible to separate our roles as teachers from our roles as human beings. We need to be political about education. According to Freire (1998b), we need political clarity regarding our stance (which proposes an understanding of man and the world), and to engage dialogically with our students. Education does not exist in isolation, disconnected from the community it finds itself in. As a faculty and an institution, it is important that we are consciously mindful that the historical, political, economic, and social systems of a country influence the education system, in general, and subject matter as well as pedagogies used in lecture halls, in particular. As lecturers, we need to ask: What kind of politics do I practise in my lecture hall? Who do I favour through my lecturing? How can I be consistent in my teaching practice? This inevitably means that you need to take a stance and have an opinion, whether right or wrong. And be open to students having a different opinion to yours. Recognising this supports the idea of a safe haven where people can differ in opinion.

\section{L: Lived experience and locality}

Nakata (2004, p. 12) asserted that "we might teach ourselves and our children about our 'locatedness' or 'situatedness' in relation to what is around us, in this case, not environmental elements only, but also knowledge systems" of our respective communities. All knowledge is historical and contextual and must be taught in such a way. Our connected learning in HEIs ought to be connected to experiential learning, contextual learning, problem-based learning, constructivism, outdoor education, indigenous education, environmental and ecological education, as well as other approaches that are concerned with context and the peoples' value of learning from specific places, communities, or regions. Do you openly discuss issues of race, and social justice with your students? Which strategies do you employ to deal with students' background knowledges and lived experience in your lecture hall? To what extent do you incorporate students' lived experiences in what you teach? Thus, through incorporating students lived experiences in the teaching process and acknowledging the local context, a sense of community will be enhanced.

\section{A: Agency}

As researchers, we recognise that as a faculty, we need to take individual and collective action to transform our places of learning. We need agency to make it more reasonable and more just and democratic through the content and pedagogies as we reflect on our own dispositions. As agents of change, lecturers need to make an analysis of their own situation, looking at what foreshadows their pedagogies. This demands persons to look at their own historicity asking the questions: How did I come to see things the way that I do? Why do I do the things the way I do? How do we assist colleagues who do not understand or agree with the decolonisation project? How do I stay committed to bring about the required change? Freire (1970) contended that lecturer agency emerges only through restless, impatient, continuing, hopeful, and critical enquiry with other people. 


\section{C: Critical consciousness}

Battiste (2000, p. xvi) argued that if decolonisation is to achieve its principal goals of restoring dignity (healing) and applying fundamental human rights to indigenous peoples, then it must necessarily entail a "complex arrangement of conscientisation, resistance and transformative praxis"- it must entail a consciousness that is mindful that reality needs to be transformed and social change provoked. The PLACES framework requires persons to think critically about their situation, in the world and the faculty specifically, and what actions are open to them to improve their situation. So, how do I constantly create a critical awareness for myself and my students? People need to realise that critical consciousness is an ongoing process of healing, where people are able to stop, reflect, evaluate, and start all over again.

\section{E: Exposure and engagement}

The PLACES framework offers participants a space where people can collaboratively engage in meaningful ways, and allows for sharing between different cultures. It becomes relevant to discern how we ensure that the educational content we teach is appropriate to our students' lives, and that our methods are based on dialogue and respect. How do we include local knowledges, experiences, skills, and values in our curriculum? There are no easy answers within HEIs, but we need to continuously search for and create new pathways that are useful and beneficial to all. Pruyn and Malott (2013) encouraged the use of collaborative teams to enhance the implementation of decolonisation practices because they create a safe space to share experiences and learn from each other.

\section{S: Student and self-interchangeability}

Freire (1978) convincingly argued for a strong partnership between teachers and studentslearning from and working with one another. Teachers need to see and value students as allies in common struggles for social justice (Perry, 2003). In the space of higher education, it is important for lecturers to know when to lead and when to follow using a pedagogy of love (Darder, 2017) to encourage student voices. The pedagogy of love, which forms the core of the metaphor butterfly referred to above, encourages democratic classroom spaces as places where the lecturer and the student together constitute a community of inquiry, where the lecturer is also a co-inquirer, a participant who tries to uncover meaning as a co-learner (Apple \& Beane, 2007) collaboratively with their students. Or as Freire (1978) said, being in communion with one another. How do you as a lecturer exercise your authority without being authoritarian, in a democratic and respectful manner? How do you as a lecturer stay true to your stance, and still respect your students who might think differently, to you? How do you share power in your classroom, and not feel intimidated? We propose that lecturers reflect on these guiding questions as they navigate towards a place of possibility and reevaluate their dispositions towards decolonising the curriculum. 


\section{Conclusion}

As we continue to reflect on lecturer dispositions in higher education, we are mindful of Freire's (1994) inspiring call to action and to responsiveness in our places of learning.

Progressive educators ought to. . keep their eyes always open, along with their ears, and their whole soul-open to the pitfalls of the so-called hidden curriculum. Hence, the exigency they must impose on themselves of growing ever more tolerant, of waxing ever more open and forthright, of turning ever more critical, of becoming ever more curious. ... The more tolerant, the more open and forthright, the more critical, the more curious and humble they become, the more authentically they will take up the practice of teaching. (pp. 80-81)

PLACES challenges all in the higher education sector to expand the scope of their theory, inquiry, and practices. Most importantly, it challenges lecturers to read the texts of their own lives, and to ask constantly what needs to be transformed and what needs to be conserved. The primary value of PLACES is that it serves to strengthen connections to self and to others as we facilitate collaborative spaces to decolonise the curriculum.

\section{References}

Alexander, N. (2014). Interviews with Neville Alexander: The power of languages against the language of power. Durban, RSA: University of KwaZulu-Natal Press.

Apple, M., \& Beane, J. (2007). Democratic schools: Lessons in powerful education. New York, NY: Heinemann.

Asimaki, A., \& Koustourakis, G. (2014). Habitus: An attempt at a thorough analysis of a controversial concept in Pierre Bourdieu's theory of practice. Social Sciences, 3(4), 121-131.

Banks, J. (2003). Teaching strategies for ethnic studies. Boston, MA: Allyn \& Bacon.

Battiste, M. (2000). Introduction: Unfolding the lessons of colonization. In M. Battiste (Ed.), Reclaiming Indigenous voice and vision (pp. xvi-xxx). Vancouver, Canada: University of British Columbia Press.

Battiste, M. (2013). Decolonizing education, nourishing the learning spirit. Vancouver, Canada: UBC Press/Purich.

Bautista, E. (2018). Transformative youth organizing: A decolonizing social movement framework (Doctoral dissertation, Loyola Marymount University). Retrieved from https://digitalcommons.lmu.edu/cgi/viewcontent.cgi?article=1524\&context=etd 
Bondy, E., Beck, B., Curcio, R., \& Schroeder, S. (2017). Dispositions for social justice teaching and learning. Journal of Critical Thought and Praxis, 6(3), 1-16.

Bourdieu, P. (1977). Outline of a theory of practice. Cambridge, UK: Cambridge University Press.

Bourdieu, P. (1984). Distinction: A social critique of the judgment of taste. London, UK: Routledge.

Bourdieu, P. (1990a). In other words: Essays towards a reflexive sociology. Cambridge, UK: Polity Press.

Bourdieu, P. (1990b). The logic of practice. Stanford, CA: Stanford University Press.

Bourdieu, P. (1998). Practical reason: On the theory of action. Stanford, CA: Stanford University Press.

Bozalek, V., Carolissen, R., \& Leibowitz, B. (2013). A pedagogy of critical hope in South African higher education. In V. Bozalek, B. Leibowitz, R. Carolissen, \& M. Boler (Eds.), Discerning critical hope in educational practices (pp. 40-54). Abingdon, UK: Routledge.

Braun, V., \& Clarke, V. (2006). Using thematic analysis in psychology. Qualitative Research in Psychology, 3, 77-101.

Darder, A. (2015). Freire and education. New York, NY: Routledge.

Darder, A. (2017). Reinventing Paulo Freire: A pedagogy of love. New York, NY: Routledge.Darder, A., Baltodano, M. P., \& Torres, R. D. (2009). The critical pedagogy reader. New York, NY: Routledge.

De Sousa Santos, B. (2014). Epistemologies of the South: Justice against epistemicide. New York, NY: Routledge/Taylor \& Francis.

Fataar, A. (2018). Decolonising education in South Africa: Perspectives and debates. Educational Research for Social Change, 7, vi-ix.

Freire, P. (1970). Pedagogy of the oppressed. New York, NY: Herder \& Herder.

Freire, P. (1978). Pedagogy in process: The letters to Guinea-Bissau (C. St. John Hunter, Trans.). New York, NY: Continuum.

Freire, P. (1994). Pedagogy of hope: Reliving Pedagogy of the Oppressed (R. R. Barr, Trans.). New York, NY: Continuum.

Freire, P. (1998a). Pedagogy of freedom: Ethics, democracy, and civic courage (P. Clarke, Trans.). Lanham, MD: Rowman \& Littlefield. 
Freire, P. (1998b). Cultural action for freedom. Harvard Educational Review, 68(4), 471521.

Freire, P. (2004). Pedagogy of indignation. Boulder, CO: Paradigm.

Freire, P. (2007). Daring to dream: Toward a pedagogy of the unfinished (A. K. Oliveira, Trans.). Boulder, CO: Paradigm.

Freire, P., \& Macedo, D. (1995). A dialogue: Culture, language and race. Harvard Educational Review, 65(3), 377-402.

Freire, P., \& Shor, I. (1987). What is the "dialogical method" of teaching? Journal of Education, 169(3), 11-31.

Geduld, D., \& Sathorar, H. (2016). Leading curriculum change: Reflections on how Abakhwezeli stoked the fire. South African Journal of Education, 36(4), 1-13.

Ginwright, S. (2010). Black youth rising: Activism and radical healing in urban America. New York, NY: Teachers College Press.

Gordon, H. R. (2010). We fight to win: Inequality and the politics of youth activism. Piscataway, NJ: Rutgers University Press.

Goulet, L., Linds, W., Episkenew, J., \& Schmidt, K. (2011). Creating a space for decolonization: Health through theatre with indigenous youth. Native Studies Review, 20(1), 89-116.

Heleta, S. (2018). Decolonizing knowledge in South Africa: Dismantling the "pedagogy of big lies." Ufahamu: A Journal of African Studies, 4(2), 46-65.

Jansen, J. D. (2009). Knowledge in the blood: Confronting race and the apartheid past. Stanford, CA: Stanford University Press.

Leedy, P., \& Ormrod, J. (2005). Practical research: Planning and design. Upper Saddle River, NJ: Prentice Hall.

Lincoln, Y. S., Lynham, S. A., \& Guba, E. G. (2011). Paradigmatic controversies, contradictions, and emerging confluences, revisited. In N. K. Denzin \& Y. S. Lincoln (Eds.), The SAGE handbook of qualitative research (4th ed., pp. 97-128). Los Angeles, CA: SAGE.

Lipman, P. (2011). The new political economy of urban education: Neoliberalism, race, and the right to the city. New York, NY: Taylor \& Francis.

Mackinlay, E., \& Barney, K. (2012). Unknown and unknowing possibilities: Transformative learning, social justice and decolonizing pedagogy in Indigenous Australian studies. The Australian Journal of Indigenous Education, 41, 10-17. 
Mbembe, A. (2015). Decolonizing knowledge and the question of the archive. Retrieved from http://wiser.wits.ac.za/system/files/Achille\%20Mbembe\%20-

20Decolonizing\%20Knowledge\%20and\%20the\%20Question\%20of\%20the\%20Archi ve.pdf

Mbembe, A. (2016). Decolonising the university: New directions. Arts \& Humanities in Higher Education 15(1), 29-45.

McDonough, P., \& Polzer, J. (2012). Habitus, hysteresis and organizational change in the public sector. Canadian Journal of Sociology, 37(4), 357-379.

Miles, M. B., \& Huberman, A. M. (1994). Qualitative data research: An expanded sourcebook (2nd ed.). Thousand Oaks, CA: SAGE.

Mitchie, G. (2012). We don't need another hero: Struggle, hope, and possibility in the age of high-stakes schooling. New York, NY: Teachers College Press.

Nakata, M. (2004). Indigenous Australian studies and higher education. The Australian Journal of Anthropology, 17(3), 265-275.

Navarro, Z. (2006). In search of cultural interpretation of power. IDS Bulletin, 37(6), 11-22.

Ngũgĩ wa Thiong'o. (1981). Decolonising the mind: The politics of language in African literature. Nairobi, Kenya: East African Educational.

Oelofsen, R. (2015). Decolonisation of the African mind and intellectual landscape. Phronimon, 16(2), 130-146.

Palmer, P. J. (1997). The courage to teach: Exploring the inner landscape of a teacher's life. San Francisco, CA: Jossey-Bass.

Perry, T. (2003). Up from the parched earth: Toward a theory of African-American achievement. In T. Perry, C. Steele, \& A. G. Hilliard III (Eds.), Young, gifted, and black: Promoting high achievement among African-American students (pp. 1-108). Boston, MA: Beacon Press.

Pruyn, M., \& Malott, C. (2013). Critical multicultural social studies and the socialist challenge. In C. Malott, M. Cole, \& J. Elmore (Eds.), Teaching Marx: The socialist challenge (pp. 161-206). Charlotte NC: Information Age.

Ramoupi, N. (2014). African research and scholarship: 20 years of lost opportunities to transform higher education in South Africa. Ufahamu: A Journal of African Studies, $38(1), 268-286$.

Ravitch, S. M., \& Carl, N. M. (2016). Qualitative research: Bridging the conceptual, theoretical, and methodological. Los Angeles, CA: SAGE. 
Rubin, H. J., \& Rubin, I. S. (2012). Qulaitative interviewing: The art of hearing data (3rd ed.). Los Angeles, CA: SAGE.

Sadeghi, S. (2008). Critical pedagogy in an EFL teaching context: An ignis fatuous on an alternative approach? Journal for Critical Education Policy Studies, 6(1), 276-295.

Santos, B. (2014). Epistemologies of the South: Justice against epistemicide. Boulder, CO: Paradigm.

Sardar, Z. (2008). I think it would be good if certain things were said: Fanon and the epidemiology of oppression (Foreword). In F. Fanon 1967, Black skins, white masks (pp. vi-xx). London, UK: Pluto Books.

Sathorar, H., \& Geduld, D. (2018). Towards decolonizing teacher education: Reimagining the relationship between theory and praxis. South African Journal of Education, 38(4). Retrieved from http://www.sajournalofeducation.co.za

Soudien, C. (2015). Of false-starts, blind spots, cul-de-sacs and legitimacy struggles: The curriculum debate in South African Higher Education. Southern African Review of Education, 21(1), 19-38.

Splitter, L. J. (2010). Dispositions in education: Nonentities worth talking about. Educational Theory, 60(2), 203-230.

Suransky, C., \& van der Merwe, J. C. (2014). Transcending apartheid in higher education: Transforming an institutional culture. Race Ethnicity and Education, 19(3), 577-597.

Swartz, D. (1997). Culture and power. The sociology of Pierre Bourdieu. Chicago, IL: University of Chicago Press.

Taylor, P. C., \& Medina, M. N. (2013). Educational research paradigms: From positivism to multi-paradigmatic. The Journal of Meaning-Centered Education, 1(2), 1-13.

The National Council for Accreditation of Teacher Education, Standards, Procedures, and Policies for Accreditation of Professional Development Education Units. (2006). NCATE Report. Washington DC: CHEA \& CIQG.

Villegas, A. M. (2007). Dispositions in teacher education: A look at social justice. Journal of Teacher Education, 58(5), 370-380. 